\title{
A preguiça e a reprodutibilidade técnica: um diálogo conceitual entre Paul Lafargue e Walter Benjamin
}

\author{
Rosana Jardim Candeloro ${ }^{1}$ \\ Rafael Petry Trapp ${ }^{2}$
}

\section{Resumo}

$\mathrm{O}$ artigo que ora se apresenta pretende resgatar as contribuições da obra de Paul Lafargue, $O$ direito à preguiça, de 1881, destacando o fato de que o mesmo apontava a preguiça como dispositivo fundamental para a salvação do proletariado e a base para a construção de cultura. Nesse sentido, tenta-se aproximar o conceito de preguiça de Lafargue do conceito de reprodutibilidade técnica de Walter Benjamin, sinalizado na abordagem que faz do cinema no texto A obra de arte da época de suas técnicas de reprodução, publicado em 1936. Para tal empreendimento teórico, realizou-se uma pesquisa bibliográfica, a partir da análise dos textos primários e dos comentadores das obras de ambos os autores. Conclui-se que é legítima a aproximação das obras mencionadas dos dois autores, ambos marxistas de formação, na medida em que a reprodutibilidade técnica pode ser, nos dois textos analisados, um princípio regulador da produção de cultura e de arte entre as classes trabalhadoras. Da mesma forma, a preguiça como produtora de cultura, central na proposta lafarguiana de redenção do proletariado, pode ser relacionada ao caráter revolucionário do cinema em Benjamin, produto da reprodutibilidade técnica, potencializado pela preguiça.

Palavras-chave: Reprodutibilidade técnica. Cinema. Preguiça. Trabalho. Marxismo.

\section{Laziness and tecnical reproducibility: a conceptual dialogue between}

\section{Paul Lafargue and Walter Benjamin}

\begin{abstract}
This article intends to rescue the contributions of the work of Paul Lafargue, The Right to Be Lazy, from 1881, highlighting the fact which he pointed the laziness as a fundamental device for the salvation of the proletariat and the basis for the construction of culture. In this sense, we attempt to approach the Lafargue's concept of laziness from the concept of reproducibility of Walter Benjamin, signalized in his speech about the cinema in the text The work of art in the age of mechanical reproduction, published in 1936. For this theoretical achievement, we carried out a literature research, based on the analysis of primary texts and commentators of the works of both authors. We conclude that it's legitimate the approximation between the mentioned works of the two authors, both Marxists, since the mechanical reproduction can be analyzed in both texts, a principle regulator of production of culture and art among the working classes.

\footnotetext{
${ }^{1}$ Docente de Filosofia e Estética da Universidade da Santa Cruz do Sul - UNISC/RS. E-mail: rosanajardimc@gmail.com

${ }^{2}$ Acadêmico do Curso de História e bolsista de pesquisa PUIC-Voluntário da Universidade de Santa Cruz do Sul - UNISC/RS. E-mail: rafaelpetrytrapp@ hotmail.com
} 
Likewise, the laziness as a producer of culture, which is central on Lafargue's proposal of redemption of the proletariat, may be related to the revolutionary nature of cinema in Benjamin, a product of mechanical reproduction, augmented by the laziness.

Key-words: Mechanical reproduction. Cinema. Laziness. Work. Marxism.

\section{Introdução}

O presente artigo objetiva realizar, através de revisão bibliográfica, uma aproximação entre o pensamento do ativista político e teórico marxista Paul Lafargue (1842-1911), relacionando-o com as ideias de reprodutibilidade técnica e cinema do pensador alemão Walter Benjamin (1892-1940). Para tal, consideram-se como significativos aportes teóricos, respectivamente, o livro de Lafargue, $O$ direito à preguiça, e o ensaio de Benjamin, A obra de arte na era da reprodutibilidade técnica. Nessa obra, publicada pela primeira vez em 1936, Benjamin posiciona-se criticamente com relação à "degradação" da arte pela perda de sua "aura", em função dos novos modos de reprodutibilidade técnica surgidos no século XIX, inicialmente a fotografia, e, em um segundo momento, o cinema - este em uma escala muito maior.

Apesar disso, e de seu indevido uso pelos fascismos e totalitarismos, Benjamin vê no cinema um potencial instrumento de difusão de ideias e de conscientização das massas. Lafargue, em $O$ direito à preguiça, originalmente publicado em 1881, seu livro mais conhecido e comentado, estabelece uma série de críticas ao que considerava a "religião do trabalho", na visão do autor, a verdadeira fonte de opressão dos trabalhadores.

A primazia e a importância que Benjamin atribui à reprodutibilidade técnica, consubstanciada no cinema como instrumento emancipatório do homem e das massas, podem ser consideradas, sob uma perspectiva ampla e devidamente contextualizada, de alguma maneira afinada ao projeto de Lafargue, que primava pelo cultivo da preguiça e pela diminuição do número de horas de trabalho - utilizando-se do expediente das máquinas - como forma de emancipação rumo à dignidade e à plenitude da existência humana.

Assim sendo, procuram-se questões no texto benjaminiano que se relacionem com a temática e as propostas expressas por Lafargue em $O$ direito à preguiça, em especial no que se refere ao trabalho e suas implicações teóricas e práticas, tema 
sobejamente discutido por Lafargue no livro. Trabalhando metodologicamente uma temática específica, estuda-se o trabalho de acordo com especificidades concernentes ao tempo e espaço, às rupturas, às transições e às continuidades nas diversas configurações das práticas referentes ao trabalho nos diferentes momentos históricos em que escrevem Lafargue e Benjamin. Evidentemente que essa metodologia não impede que outras instâncias do pensamento desses autores sejam abordadas, pois as possibilidades são múltiplas, mas não se tem aqui espaço para uma análise mais profunda e extensa que abarque essa multiplicidade.

Antes de adentrar as propostas de Lafargue convém que se faça uma análise de como Benjamin pensa a reprodutibilidade técnica e o cinema. A ideia benjaminiana de cinema constitui-se paradigma importante contemporaneamente, no que se refere, por exemplo, aos estudos de teoria da arte e do cinema. Contudo, a maneira de como podese relacionar conceitualmente as ideias de Benjamin sobre cinema e reprodutibilidade técnica com as proposições de Lafargue no que se refere ao Direito à preguiça é tema que será analisado mais detidamente em um segundo momento, no tópico subsequente.

\section{Walter Benjamin e o cinema}

Filósofo, escritor, ensaísta, tradutor, crítico de arte, alemão, judeu. Walter Benjamin transitou por diversas áreas do conhecimento e esteve profunda e intrinsecamente ligado às questões mais prementes do pensamento e da realidade difícil de seu tempo. Intelectual multifacetado, não deixou de também se envolver nos debates e nas críticas às concepções - já em crise na época em que sua produção intelectual é mais ativa, ou seja, no contexto do entre-guerras europeu, após um primeiro grande conflito que deixara milhões de mortos e um rastro de destruição - de modernidade e progresso.

O texto aqui analisado reflete em si muitas das tensões da época em que é pensado, escrito e publicado. O ensaio "A obra de arte na época da reprodutibilidade técnica" é publicado em 1936, três anos após a ascensão do nazismo e de Hitler à chancelaria alemã, em 1933, e outros três anos antes do início da Segunda Grande Guerra, em 1939. A respeito desse trabalho, em carta enviada em 24 de outubro de 1935 para Gershom Sholem, Benjamin diz que:

Este avançou bastante ultimamente, graças a algumas constatações básicas no terreno da história da arte. Junto ao esquema histórico que esbocei há cerca 
de quatro meses, estas linhas básicas sistemáticas formarão uma espécie de rede graduada, na qual serão anotados cada um dos elementos. Estas reflexões fundamentam a historia da arte no século XIX no entendimento da sua situação atual, como nos a vivenciamos. Mantenho-as sob o mais estrito sigilo por serem bem mais sujeitas a roubo do que a maioria dos meus pensamentos. Seu titulo provisório é: "Das Kunstwerk im Zeitalter seiner technischen Reproduzierbarkeit ["A Obra de Arte na Época da Reprodutibilidade Técnica”]. (BENJAMIN; SCHOLEM, 1993, p. 234-235).

Pode-se perceber a partir daí o tanto de envolvimento de Benjamin e o modo como descreve seu trabalho, quase entusiasticamente. Ciente de sua importância, receia torná-lo passível de ser roubado. Porém, para ventura nossa, o trabalho não foi roubado ou perdido. Pelo contrário, tornou-se um de seus textos mais conhecidos e analisados $a$ posteriori, alvo dos mais diversos usos e interpretações. O que se tentará fazer aqui não tem o caráter senão de um breve comentário com um fim específico, que é o de tentar entender a função essencial que o cinema adquire no pensamento de Benjamin.

O ensaio de Benjamim trata mais especificamente da influência no campo artístico das modernas técnicas de reprodução surgidas no século XIX e do consequente alcance e difusão da obra de arte. O advento da fotografia, enquanto técnica de reprodução, na primeira metade do século XIX, subverte a significação da obra de arte, na medida em que lhe destitui o que é sua própria função e sentido, a saber, o seu valor de culto, sua autenticidade e unicidade. Para Benjamin, a obra de arte autêntica teria um hic et nunc, "aqui e agora", que lhe conferiria sua originalidade e seria o elemento próprio da sua autenticidade. A reprodutibilidade técnica moderna, com a fotografia e o cinema, apesar de manter o conteúdo, desvaloriza o hic et nunc da obra de arte. Benjamin se utiliza do conceito de aura, para dizer que o que na obra de arte é atingido pela reprodutibilidade desenfreada é a sua aura. Ele a define, de maneira um tanto quanto poética e enigmática, como sendo "a única aparição de uma realidade longínqua, por mais próxima que esteja." (BENJAMIN, 1975, p.15).

Esse processo de perda do valor aurático estaria ligado à progressiva desvalorização e perda da tradição, que, por sua vez, estaria conectado à ascensão dos movimentos de massa da época, que tinham no cinema seu agente e expressão principal. Para Benjamin, o cinema liquida a tradição no seio da herança cultural, em função do seu caráter catártico e destrutivo. Subverte-se, assim, a bases ritualística da obra de arte, para fundamentá-la em uma práxis diferente, componente essencial do pensamento estético benjaminiano: a política. Essas modificações operadas pela fotografia e, especialmente, pelo cinema, afetaram profundamente a natureza e a essência da obra de 
arte, em dois sentidos possíveis: um negativo, o da perda da aura e da autenticidade da obra de arte e, por conseguinte, da tradição; outro positivo, ao democratizar, através do cinema, o acesso à cultura, tendo em vista as massas e suas exigências revolucionárias.

O cinema, de acordo com Benjamin, é um instrumento que, para além da revolução socialista, funcionaria como que sendo um contraponto à estetização da política levada a cabo pelos fascismos - mormente o nazismo - que souberam se aproveitar do cinema como forma de propaganda política. Benjamin identifica na União Soviética da época uma produção cinematográfica mais afeita aos princípios do socialismo, em que os atores cumpririam o próprio "papel social" e seriam representados frente às objetivas das filmadoras de maneira naturalizada, ao contrário do que acontecia aos atores submetidos aos cânones cinematográficos capitalistas, em que a pessoa do ator é destituída de sua própria aura. Apesar disso, o estatuto de representação da realidade operado pelo cinema é muito mais significativo,

[...] pois se ela (a imagem do real) atinge esse aspecto das coisas que escapa a qualquer instrumento - o que se trata de exigência legítima de toda obra de arte - ela só o consegue exatamente porque utiliza instrumentos destinados a penetrar, do modo mais intensivo, no coração da realidade (BENJAMIN, 1975, p. 26).

No cinema é tudo muito rápido e instantâneo, sequencial, não havendo tempo para a contemplação. Para a arte convencional, como a pintura, que exige a concentração, o cinema responde com a abertura de novas possibilidades de apreensão do real.

O próprio crescimento do público transformou o seu modo de participação. Apesar das críticas feitas ao cinema e da depreciação advinda do fato de que o filme se prestaria somente à diversão, não contendo valor artístico, em oposição à "atitude séria e concentrada exigida pela arte", que faz quem se concentra nela "mergulhar" dentro da obra, no cinema é a obra que entra na "massa", ao mesmo tempo em que pode vir a mobilizá-la.

Benjamin faz ainda uma série de considerações sobre os aspectos técnicos do cinema e a sua relação com o teatro e os elementos da atuação, e as consequências de tudo isso para a própria percepção que o homem e, por conseguinte, as massas, passam a ter de si e do mundo, ao tomarem contato com um filme. Além disso, o cinema teria 
ainda outro valor fundamental, o de permitir uma crítica das concepções antigas de arte a despeito de seu valor enquanto tal.

Com o cinema, as atitudes das massas com relação à arte mesma são modificadas. "Muito retrógrada face a um Picasso, essa massa torna-se bastante progressista diante de um Chaplin, por exemplo." (BENJAMIN, 1975, p. 27). Essa mudança de atitude é importante e essencial, na medida em que "no cinema, o público não separa a crítica da fruição", as "reações individuais [...] ficam determinadas desde o começo pela virtualidade imediata de seu caráter coletivo.” (BENJAMIN, 1975, p. 27).

Outra consideração interessante presente no texto é o paralelo que Benjamin estabelece entre o dadaísmo e o cinema. O cinema, enquanto forma de expressão, conteria em si alguns dos pressupostos dadaístas, como a ideia de choque, de ferir a percepção, a "não-contemplação" da obra. Através das mudanças de lugar e de cena, o filme produziria efeitos análogos, só que desvinculados da "moralidade" conceitual dadaísta. De acordo com Konder (1999, p. 79),

\footnotetext{
Na representação das formas em movimento, para as quais não atentávamos suficientemente, o cinema conseguiu realizar aquilo que os dadaístas tinham tentado, mas não tinham conseguido fazer. $\mathrm{O}$ movimento é visto e compreendido como movimento humano, isto é, pode conquistar a unidade inerente à práxis, no sentido marxista da palavra (a atividade pela qual os seres humanos transformam a realidade e se transformam a si mesmos).
}

Benjamin considerava o cinema dentro do contexto mais amplo das novas formas de percepção e das tarefas revolucionárias inerentes a elas. Assim, enfatizava, na parte final de seu ensaio, o quanto o fascismo (leia-se principalmente: nazismo) tendia a estetizar a política, ao atribuir valor de culto às lideranças políticas. Para Benjamin, isso levaria necessariamente à guerra. O "Manifesto de Marinetti" (BENJAMIN, 1975) produção do fascismo italiano, é um dos documentos que glorificava a guerra, dotandoa de beleza, de valor estético, uma "estética de guerra". Benjamin intenta, com seu esteticismo otimista, quanto às possibilidades do cinema, de alguma forma fazer frente à ascensão do autoritarismo, do racismo e do belicismo. Em resposta à estetização da política levada a cabo pelos regimes totalitários e ditatoriais, o que Benjamin propõe é uma politização da arte através do cinema.

Após essa breve análise do cinema no pensamento de Walter Benjamin, procede-se ao estudo de um livro de um autor pouco conhecido no meio acadêmico, 
mas especialmente conhecido no segmento da militância operária e marxista: $O$ direito à preguiça, de Paul Lafargue.

\section{Paul Lafargue e $O$ direito à preguiça}

Escritor, militante político, periodista, socialista, Paul Lafargue nasceu em 15 de janeiro de 1842 em Santiago de Cuba, na ilha ainda espanhola. Mestiço, filho de franceses emigrados, de ascendência caraíba e haitiana, Lafargue viveu parte da infância em Cuba e por um pequeno período na Louisiana. Realizou seus estudos primários em Santiago. Em 1851, sua família mudou-se para Bordeaux, na França (MAERK, 2000). Nesse país, Lafargue viveu grande parte de sua vida e desenvolveu muitas de suas inúmeras atividades. Em 1861 ingressa na Faculdade de Medicina de Paris; porém, aí não conclui seus estudos, em função de uma proibição do Governo francês de $1865 \mathrm{em}$ represália às suas atividades políticas, mas em Londres (MAERK, 2000).

Nessa época, o jovem Lafargue já se encontra envolvido com as questões políticas mais prementes, mormente a forte crítica e oposição a Napoleão III e ao Segundo Império francês (MARIE, s. d.). Em 1865 filia-se à seção francesa da Associação Internacional dos Trabalhadores, entidade fundada por Karl Marx em Londres (MARIE, s. d.), e começa de maneira efetiva sua carreira como militante profissional da causa operária e socialista.

No mesmo ano vai à Inglaterra para participar da fundação da Primeira Internacional. Nessa ocasião conhece Karl Marx, de quem mais tarde, em 1868, se tornaria genro, ao desposar sua filha Laura. Se se pode dizer que Lafargue estava sob a influência intelectual do positivismo comtiano, dos iluministas, de autores socialistas e anarquistas como Fourier, Saint-Simon e Proudhon, a partir desse momento Marx será para ele um mestre e um guia intelectual (MAERK, 2000), tornado-se Lafargue um dos maiores defensores e difusores do marxismo no século XIX. Também se envolveu com o movimento operário na Espanha, sendo incumbido por Engels, seu padrinho de casamento, de difundir aí a doutrina marxista. Representou Espanha e Portugal no Congresso Internacional de Haia em 1872, assistindo o sogro Karl Marx nessa ocasião. Sua atuação foi decisiva para a posterior criação do Partido Socialista Obrero Espanhol (PSOE), em 1879 (MARIE, s. d.). 
Em 1873 muda-se novamente para Londres, onde trabalhou por pouco tempo como litógrafo. $\mathrm{O}$ insucesso o levou a pedir ajuda financeira de Engels, que termina por lhe possibilitar contato com o movimento operário francês. Na França, em 1879, tornase um dos fundadores do Partido Operário Francês, ao qual dedicou boa parte de suas energias pessoais, militando ativamente nos anos seguintes através de diversas publicações e debates (MAERK, 2000). Marie (s. d., p. 7) assevera que "jusqu'à sa mort il se dévouera à la cause de la révolution socialiste par écrit et par la parole." [até sua morte ele vai se dedicar à causa da revolução socialista pela escrita e pela palavra].

A obra, objeto de nossa análise, $O$ direito à preguiça, aparece publicada no jornal L'Egalité, em 1880, ano em que Lafargue começa a trabalhar como editor desse mesmo periódico. Segue em atividade intensa até 1911, quando, no dia 25 de novembro, se suicida juntamente com sua esposa Laura. O tema do suicídio de Paul e Laura, bem como o de Benjamin, será retomado ao final deste trabalho.

$O$ direito à preguiça, publicado nos meses de junho, julho e agosto de 1880 no jornal L'Egalité, obteve sucesso e difusão imediatos e impressionantes. Em poucos anos, encontrava-se traduzido em vários idiomas. Seu sucesso foi tal que

\footnotetext{
Vários autores são unânimes em considerar $O$ direito à preguiça como um clássico do movimento operário. Somente na Rússia, no período 1905-1907, o panfleto alcançou 17 edições. Era, por volta de 1906, o texto mais editado, mais traduzido e mais lido pelo movimento operário europeu depois do Manifesto do Partido Comunista de Marx e Engels (DOMMANGET apud HARDMAN, 1980, p. 19).
}

Tamanho sucesso na Europa e nos meios operários internacionais não ensejou uma publicação em língua portuguesa para o livro de Lafargue. A primeira edição em língua portuguesa só apareceu em 1980, portanto 100 anos após sua primeira publicação. Hardman (1983) escreve que, mesmo com esse atraso centenário, a imprensa operária brasileira anterior a 1920 tinha conhecimento do famoso panfleto.

Para Albornoz (2008, p. 3), o atraso na publicação da obra pode ser explicado em função da "dificuldade para a circulação de idéias de esquerda durante a ditadura militar, sobretudo entre 1968 [...] e 1979, quando o Brasil começou a superar a censura da expressão de idéias com a anistia política." Ainda, outra explicação possível seria a da burocratização crescente do movimento operário e do sindicalismo brasileiro a partir dos anos 1930 (HARDMAN apud ALBORNOZ, 2008), quando da revolução varguista, que daria especial atenção à situação delicada da organização dos trabalhadores. 
De 1980 para cá, várias edições de $O$ direito à preguiça vêm sendo apresentadas ao público brasileiro, tornando-se inegável a difusão e o interesse pelas ideias e preceitos lafarguianos, no que se refere a uma gama variada de temas, tais como política, utopia, trabalho, tecnologia, industrialização, consumo, sociedade etc. Apesar da fecundidade patente não só deste trabalho, mas de inúmeros outros escritos de Lafargue, pouco se tem escrito no Brasil, mesmo na perspectiva marxista, sobre esse autor.

Ciente desta carência, este trabalho visa a colaborar no sentido de expandir o conhecimento sobre sua vida, sua obra, suas ideias e as possibilidades de estudo que se vislumbram, tendo como referência outras instâncias da atividade humana, não só a economia e as relações de produção, temas muito cotejados pelas análises do materialismo histórico. Aqui, especificamente, empreende-se uma análise de sua obra e de sua relação com outros autores e outros campos da ação humana, tais como as artes e a cultura, trazendo suas questões para um diálogo com as que o presente impõe ao historiador.

No tocante à cultura, com base nas ideias propostas em $O$ direito à preguiça, tem-se aqui como objeto principal de análise o cinema, em relação ao "cinema" benjaminiano. O cinema, arte do movimento, consoante à celeridade da modernidade, tem papel central em múltiplas e variadas análises de autores que escrevem na primeira metade do século XX, como Theodor Adorno, Sergei Eisenstein, Sigfried Kracauer e Walter Benjamin.

Não consta que Paul Lafargue tenha dedicado algum estudo ou apreciação sobre o cinema e seu advento, mas tem-se como certo o fato de Lafargue estar atento às grandes questões de seu tempo. O cinématographe foi certamente uma delas. Em 1880, ano da primeira publicação de $O$ direito à preguiça, os irmãos Lumière ainda não haviam apresentado ao mundo o aparelho de reprodução sequenciada de imagens que, a partir de 1896, mudaria a percepção do homem de si e da realidade do mundo, agora em movimento. Nesse ano, aliás, Lafargue escreve um trabalho intitulado Les origines $d u$ Romantisme, o que atesta sua ligação e interesse pelos temas da cultura e da arte.

Lafargue seguramente tinha conhecimento da reprodutibilidade técnica tal como pensada por Benjamin, senão o cinema, em 1880, ao menos a fotografia e o papel decisivo e revolucionário que ela exercia, por exemplo, no jornalismo e na difusão de 
ideias, através de reproduções em jornais e panfletos. Curiosamente, apesar disso, sabese que, no dia do suicídio de Paul e Laura, em 1911, eles haviam passeado e ido ao cinema em Paris (DE MASI, 2001).

A partir dessas informações, atentando ao contexto histórico em que Paul Lafargue pensa e escreve $O$ direito à preguiça, propõe-se, tal como explicitada na introdução, uma análise dessa obra e de como o autor aí discute o estatuto do trabalho, relacionando-os aos conceitos benjaminianos.

\section{$O$ direito à preguiça}

O direito à preguiça divide-se em quatro capítulos ou partes principais, que são, respectivamente, Um dogma desastroso, Bênçãos do trabalho, O que vem após a superprodução e Dançando de acordo com a música. Após o retumbante sucesso do texto, inicialmente publicado em periódico, o mesmo é editado na forma de livro, ao qual o autor acrescenta uma pequena Introdução e um Apêndice. Utilizar-se-á neste trabalho de análise como texto referencial o traduzido por Teixeira Coelho, edição de 1999, no qual consta também uma apreciação do texto lafarguiano por Marilena Chauí. Contemplar-se-á para comparação e análise cinematográfica apenas os quatro capítulos da edição original, excetuando-se a Introdução e o Apêndice, acrescentados em 1883.

Para Marilena Chaú, $O$ direito preguiça teria como pressuposto principal a significação do trabalho no sistema capitalista, ou seja, a divisão social do trabalho e a luta de classes. Suas principais fontes de inspiração são os escritos de Marx, seu sogro, respectivamente os Manuscritos Econômicos de 1844 e o primeiro volume de $O$ capital (CHAUÍ, 1999). Ainda segundo a mesma autora,

O direito à preguiça é um painel da sociedade burguesa, visando alcançar o proletariado no nível da consciência de classe e por isso é a crítica da ideologia do trabalho, isto é, a exposição das causas e da forma do trabalho na economia capitalista, ou o trabalho assalariado (In: LAFARGUE, 1999, p. 23).

$\mathrm{O}$ primeiro capítulo de $O$ direito à preguiça trata justamente do dogma desastroso que, na opinião do autor, seria a verdadeira fonte de opressão da classe trabalhadora nos países onde o sistema capitalista imperava e instalava-se de maneira decisiva, ou seja, o amor, a obsessão e a loucura pelo trabalho. Nas palavras do autor,

Uma estanha loucura apossa-se das classes operárias das nações onde impera a civilização capitalista. Esta loucura tem como consequência as misérias individuais e sociais que, há dois séculos, torturam a triste 
humanidade. Esta loucura é o amor pelo trabalho, a paixão moribunda pelo trabalho, levada até o esgotamento das forças vitais do indivíduo e sua prole (LAFARGUE, 1999, p. 63).

Apesar da degradação e da negatividade inerentes à sua própria condição, o trabalho continuava a ser valorizado e sacrossantificado, não só pelos operários, mas por padres, economistas, moralistas, enfim, pela sociedade como um todo. O autor tentará argumentar e demonstrar aos cultivadores do amor pelo trabalho, invocando, ao invés "das pregações de sua moral religiosa, econômica, livre-pensadora", "as terríveis conseqüências do trabalho na sociedade capitalista", afirmando que, "na sociedade capitalista, o trabalho é a causa de toda degeneração intelectual, de toda deformação orgânica." (LAFARGUE, 1999, p. 63-64).

Como exemplos para corroborar sua tese, Lafargue utiliza-se de alguns que são interessantes. Compara os "nobres selvagens", ainda não corrompidos pelo cristianismo - que, em sua faceta protestante, possui um ethos que é também glorificador do trabalho, tal como pensa, por exemplo, Max Weber, em A ética protestante e o espírito do capitalismo (2001) - aos desgraçados "escravos das máquinas" do sistema capitalista.

Argumenta que, para os antigos, como os gregos, o trabalho era visto com desprezo e repulsa, ficando a cargo apenas dos escravos. Assim, livre do trabalho, o "cidadão" grego (na verdade, um conceito relativo a um número bem pequeno de pessoas, pois excluía-se da cidadania as mulheres, os estrangeiros, os escravos, ou seja, os "não-livres") entregar-se-ia aos exercícios físicos e ao cultivo das artes e da inteligência. Ainda, Lafargue identifica no "Sermão da Montanha", de Jesus Cristo, uma pregação da preguiça, além de dizer que Jeová forneceu um dos maiores exemplos de preguiça possíveis, ou seja, o descanso na eternidade após os seis dias de trabalho da criação.

Lafargue, apesar de tão claros e relevantes exemplos de preguiça como esses, vê com pesar a escolha efetuada pelo proletariado, isto é, o direito ao trabalho, ao invés de recusá-lo ou refutá-lo. Para o autor,

o proletariado, a grande classe que abrange todos os produtores das nações civilizadas, a classe que, ao se emancipar, emancipará a humanidade do trabalho servil e fará do animal huno um ser livre - o proletariado, traindo seus instintos, desconhecendo sua missão histórica, deixou-se perverter pelo dogma do trabalho (1999, p. 67). 
Chauí (1999, pp. 24-25) enfatiza o fato de que Lafargue cogitou intitular seu trabalho como $O$ direito ao lazer, depois $O$ direito ao ócio, mas acabou optando pelo termo preguiça em função de tratar-se a mesma de um pecado capital. Assim, o autor

\begin{abstract}
visa diretamente ao que denomina 'religião do trabalho', o credo da burguesia (não só francesa) para dominar as mãos, os corações e as mentes do proletariado, em nome da nova figura assumida por Deus, o Progresso. [...] A religião é o instrumento eficaz de dominação de classe porque parece oferecer uma explicação satisfatória sobre a sociedade e garante, pela ação do clero e dos intelectuais pequenoburgueses, que o proletariado, espontaneamente incréu e ateu, seja rendido por essas idéias e crenças (In: LAFARGUE, 1999, pp. 24-25).
\end{abstract}

Essa mesma autora estabelece um interessante paralelo entre $O$ direito à preguiça e o Discurso da Servidão Voluntária, de La Boétie, pois tratam de temas correlatos, como "loucura" e "povos insensatos", além da construção semelhante de suas obras. Enquanto La Boétie pergunta-se como podem os homens nascer livres e viver em servidão como se se tratasse de algo natural, Lafargue indaga como o proletariado pode deixar-se fascinar e dominar pelo dogma do trabalho (CHAUÍ, 1999).

Bênçãos do trabalho, título obviamente irônico do segundo capítulo, versará sobre a situação de miséria, sofrimento e opressão a que estavam submetidos ou a que permitiam se submeter os proletários. Antes de propor o direito à preguiça, Lafargue procura demonstrar os danos reais que o dogma do trabalho provocou na vida dos trabalhadores das fábricas do século XIX. Essas, advindas do novo modo de produção capitalista - instaurado, primeiramente na Inglaterra no final do século XVIII, depois no resto da Europa e no mundo, em progressões temporais e condições históricas diversas, é necessário salientar -, comumente denominado industrial, constituíram-se no lugar, verdadeiro purgatório (como Lafargue diria não sem ironia), no qual os operários sofriam as agruras originadas de sua paixão pelo trabalho, incentivada pela burguesia. Assim, Lafargue (1999, p. 71) afirma que:

\begin{abstract}
As fábricas modernas tornaram-se casas ideais de correção, onde são encarceradas as classes operárias, onde se condenam a trabalhos forçados de doze e catorze horas não apenas homens, mas também mulheres e crianças. [...] E se as dores do trabalho forçado, se as torturas da fome se abateram sobre o proletariado em número maior que os gafanhotos da Bíblia, foi porque ele as invocou.
\end{abstract}

Escrevendo na França, inicialmente para leitores franceses, o autor não deixa de comentar com pesar e aborrecimento que os revolucionários de 1848 reivindicaram o direito ao trabalho, como condição e princípio revolucionário, ignorantes do fato de 
que esse era justamente a raiz e a causa de seus males e sofrimentos. "Nossa época é, como dizem, o século do trabalho; na verdade, é o século da dor, da miséria e da corrupção." (LAFARGUE, 1999, p. 73).

Descrevendo o terrível quadro que se abatia sobre o proletariado francês, como as péssimas condições de trabalho, moradia, saúde e higiene, o autor critica de modo contumaz o sistema de trabalho nas fábricas, que eram, na época, e posteriormente em um crescendo, um dos suportes do sistema e modo de produção capitalista. Nesse sentido, Lafargue conclama os operários para que

Trabalhem, trabalhem, proletários, para aumentar a riqueza social e suas misérias individuais, trabalhem, trabalhem para que, ficando mais pobres, tenham mais razões para trabalhar e tornarem-se miseráveis. Essa é a lei inexorável da produção capitalista (1999, p. 79).

Contudo, a tarefa e o esforço de conscientizar o proletariado da necessidade de se desfazer da paixão pelo trabalho e de se livrar dos conceitos e preconceitos do moralismo burguês conservador, livre-pensador, economicista e cristão, não se configurava fácil, posto que essa "moral" estava quase que totalmente internalizada na pela alma proletária. Assim, haveria de se fazer um esforço, por parte do proletariado, de "voltar a seus instintos naturais", proclamando

os Direitos à Preguiça, mil vezes mais nobres e mais sagrados que os tísicos Direitos do Homem, arquitetados pelos advogados metafísicos da revolução burguesa. É preciso que ele se obrigue a não trabalhar mais que três horas por dia, não fazendo mais nada, só festejando, pelo resto do dia e da noite (LAFARGUE, 1999, p. 84).

Aí está o cerne da proposta lafarguiana. Trabalhar não mais que três horas diárias, aproveitando o tempo livre para desfrutar do direito à preguiça e de tudo que este desfrute trouxesse de edificante e digno para o corpo e mente do Homem. Para que tal empresa fosse exequível, utilizar-se-ia o concurso justamente das máquinas, ou seja, dos meios de produção, para, através de sua capacidade praticamente infinita de reprodutibilidade, trabalharem no lugar da mão de obra humana, agora livre.

Tem-se aí um conceito já referido anteriormente, o da reprodutibilidade técnica de Benjamin, pensando, por sua vez e a seu turno, o cinema. Identifica-se, desta maneira, um possível diálogo conceitual entre Lafargue e Benjamin. Se a reprodutibilidade técnica, para Benjamin, pode ser positivada como potencial difusora das ideias de emancipação das massas proletárias através do cinema, para Lafargue o mesmo conceito pode ser pensado referindo-se ao potencial das máquinas como força 
de trabalho em substituição à já esgotada, oprimida e aviltada mão de obra proletária/fabril francesa e europeia do século XIX.

Em $O$ que vem após a superprodução, terceira parte de $O$ direito à preguiça, Lafargue desenvolve mais detalhadamente a ideia "redentora" da diminuição da jornada de trabalho nas fábricas para três horas diárias e do uso das máquinas como suporte material e laboral ao direito à preguiça. Observa o autor que, paradoxalmente, na era da paixão pelo trabalho, "a paixão cega, perversa e homicida pelo trabalho transforma a máquina libertadora em instrumento de sujeição de homens livres, pois sua produtividade os empobrece" (1999, p. 88); mesmo quando as máquinas e a tecnologia para o trabalho se aperfeiçoam e, assim, eliminam o trabalho do homem em progressão praticamente geométrica, "o operário, em vez de prolongar seu descanso na mesma medida, redobra seus esforços, como se quisesse rivalizar com a máquina." (LAFARGUE, 1999, p. 88).

A burguesia, em contrapartida, ao ajudar a instituir um sistema de produção que tem como resultado a superprodução e, por conseguinte, o consumo desenfreado, acaba por assumir o papel de não-produtora e superconsumidora, tendo de

\footnotetext{
violentar seus modestos gostos, perder seus hábitos gloriosos de há dois séculos e entregar-se ao luxo desenfreado, às depravações sifilíticas, como também teve de subtrair do trabalho produtivo uma enorme massa de homens a fim de conseguir auxiliares (LAFARGUE, 1999, p. 92).
}

Imersa em uma "preguiça" e em um imobilismo asfixiantes em função dessa situação forçada por sua própria moral e seu próprio sistema, a burguesia acabou acomodando-se, tornando-se, ao mesmo tempo, conservadora e refratária a qualquer mudança. A imagem da miserabilidade advinda das condições de trabalho e da resignação "bovina" da classe operária, mais a "degradação orgânica gerada pela paixão depravada do trabalho aumentavam ainda mais sua repulsa diante de toda imposição do trabalho e de qualquer restrição dos prazeres." (LAFARGUE, 1999, p. 94). Os proletários, por sua vez,

ingênuos, levaram ao pé da letra as teorias dos economistas e moralistas sobre o trabalho e suaram sangue na tentativa de infligir essa prática aos capitalistas. O proletariado formulou a palavra de ordem: Quem não trabalha, não come. Em 1831, Lyon levantou-se sob o lema chumbo ou trabalho; os federados de março de 1871 chamaram seu levante de Revolução do Trabalho (LAFARGUE, 1999, p. 94). 
Apesar de sua degradação, os operários franceses continuavam a pedir por mais trabalho. A mínima oportunidade de ressurgimento da paixão pelo trabalho era ocasião de mais horas de sacrifício, mais tempo despendido no alimento do vício pelo trabalho. Sucedia-se à temporada de trabalho a de desemprego e, sem emprego, a fome grassava. Lafargue considerava que, estando o dogma do trabalho tão entranhado no "coração dos operários", a quantidade de trabalho exigida pela sociedade em geral era limitada pelo consumo da mesma e pela oferta de matéria-prima,

por que devorar em seis meses o trabalho do ano todo? Por que não
distribuí-lo uniformemente pelos doze meses e forçar os operários a se
contentarem com seis ou cinco horas diárias, durante o ano, em vez de
terem uma indigestão de doze horas durante seis meses? Tendo
assegurada sua porção cotidiana de trabalho, os operários já não terão
inveja uns dos outros, já não brigarão para tirar o trabalho das mãos e
o pão das bocas uns dos outros; e, então, não estando esgotados do
corpo e da mente, começarão a praticar as virtudes da preguiça
(LAFARGUE, 1999, pp. 99-100).

Lafargue utiliza-se do exemplo da "aristocrática" Inglaterra que, desprezando a opinião dos economistas e moralistas, instituiu, em 1865, a jornada de dez horas diárias, sem que isso, na época, causasse a bancarrota da economia inglesa. A experiência inglesa atestava que era viável a redução da carga horária e o aumento dos feriados para os operários franceses, a despeito da cegueira e da falta de convencimento desses. Além da Inglaterra, Lafargue utiliza-se do exemplo norte-americano, no sentido de que a mecanização crescente da sua produção agrícola teria deixado os norte-americanos livres do trabalho. Esses preguiçosos

prefeririam morrer mil vezes a levar a vida bovina do camponês francês. O trabalho do campo, tão penoso em nossa gloriosa França, tão rico em espinhas curvadas, no oeste americano é um agradável passatempo ao ar livre a que as pessoas se entregam sentadas, fumando despreocupadamente seus cachimbos (LAFARGUE, 1999, p. 104).

O último capítulo, Dançando de acordo com a música, realiza um fechamento, profético e, ao mesmo tempo, melancólico. Diminuindo-se a carga horária de trabalho, mais tempo livre e mais forças são arregimentadas para a produção social de bens comuns. Porém, seriam necessárias leis que obrigassem os operários a "deixar" o trabalho alienado e se entregar aos prazeres da preguiça, o que incluiria atividades esportivas, comidas e bebidas sofisticadas, artes, teatro. Se o proletariado se levantasse e trouxesse à tona seu vigor e sua força incomensuráveis, para exigir, não os Direitos do Homem, nem tampouco o Direito ao Trabalho, mas para "forjar uma lei de bronze que 
proíba o trabalho além de três horas diárias, a Terra, a velha Terra, tremendo de alegria, sentiria brotar dentro de si um novo universo...” (LAFARGUE, 1999, p. 112).

Num último e desconsolado apelo, Lafargue, comparando o calvário do Cristo com as duras e dolorosas penas do proletariado, que há séculos sofre com o trabalho forçado, que lhe propicia não a alegria, mas a desesperança e a fome, exaure suas forças e alui sua saúde, evoca não a Deus, mas a Deusa: "Preguiça, tenha piedade de nossa longa miséria! Preguiça, mãe das artes e das virtudes nobres, seja o bálsamo das angústias humanas!" (1999, p. 112).

\section{Lafargue e Benjamim: entrecruzamentos}

Ainda que não se encontre expressa uma filiação de Benjamim aos conceitos de Lafargue, uma vez que ambos professavam a fé marxista, pode-se encontrar, nos escritos estéticos de Benjamim, referências esparsas às concepções de Lafargue.

Na obra de Benjamim sobre Charles Baudelaire, encontra-se, no tópico sobre o jogo e a prostituição, uma pequena citação direta de um escrito menos difundido de Paul Lafargue, a saber, As origens da crença em Deus, de 1905. Nesse trecho, Benjamin o cita: “[...] O capitalista, cuja fortuna está investida em valores da Bolsa, e que ignora as causas das oscilações dos preços e dividendos desses títulos, é um jogador profissional. [...] O inescrutável de natureza social envolve o burguês, como o inescrutável da natureza envolve o selvagem." (BENJAMIM, 1989, pp. 247-248).

Segundo observação de Benjamin, na obra Passagens (2006), os 'adeptos da preguiça' - parodiando Lafargue -, estariam imóveis na imagem da Roda da Fortuna. $\mathrm{Na}$ Idade Média, a vida ativa, a destinada ao trabalho manual, era representada por imagens humanas, que se movimentariam de acordo com a circularidade da Roda da Fortuna, ora para cima, ora para baixo. Aqueles que se dedicavam à vida contemplativa estariam, irremediavelmente, presos, sem movimento, ao eixo central da roda (BENJAMIN, 2006).

Importa ressaltar aqui a diferenciação entre o ócio clássico, de origem grecoromana, cuja essência é pejorativa para os integrantes da lógica burguesa, pois soa como indolência; e, por outro lado, a ociosidade, que, na cultura moderna, carrega o sentido precípuo de fazer uma crítica veemente à fetichização burguesa do trabalho, está mais próxima do conceito de 'preguiça', como a que encontramos na obra de Lafargue. 
Segundo Benjamin (2006, p. 843),

\begin{abstract}
A ociosidade pode ser considerada uma forma precursora de distração e de divertimento. Ela se funda na disposição do indivíduo de saborear sozinho uma sucessão aleatória de sensações. [...] surgiu entre aqueles que 'tinham tempo livre', a necessidade de se distinguir da massa dos que trabalhavam. A esta necessidade respondeu a indústria do entretenimento [...]
\end{abstract}

Hannah Arendt (2010), em sua obra A condição humana, dedica uma reflexão aprofundada ao conceito de trabalho, na sociedade de massas, em que o proletário destina seu labor à autossubsistência e à de sua família. A crítica que Arendt (2010) tece ao trabalho, nesse contexto, é que o labor conquistou um estatuto de excelência, o que antes só era possível, como na tradição grega, no domínio da ação política.

Foram vários os fatores que promoveram o labor à esfera pública e aos interesses da sociedade. Não cabe aqui a discussão desses, mas enfatizar que, dado o fato de que a excelência (areté), deslocada da matriz da ação política, passa a conformar o trabalho de interesse coletivo. Transformado o trabalho em atividade de natureza virtuosa, "os que tinham tempo livre" (BENJAMIN, 2006), diferenciavam-se da massa proletária e dedicavam-se a alguma forma de ociosidade.

\title{
Considerações finais
}

Lafargue faleceu aos 69 anos, sentado em sua sala na companhia de sua esposa Laura, de 66 anos, após terem ido ao cinema. Antes da injeção letal, escreveu uma carta-testamento que o redime diante da natureza humana. Benjamim também desapareceu desta existência de modo dramático, também de próprio punho, acometido de um rompante de violenta hybris, quando fugia da Alemanha sob a ocupação nazista.

Por motivos diferentes, ambos se suicidaram e, neste sagrado ano de 2011, ao menos, a classe operária francesa lembrar-se-á da efeméride dos 100 anos do desaparecimento de Paul Lafargue e Laura Marx.

Na época em que Thomas Morus escreveu A Utopia, em 1516, os camponeses e operários ingleses tinham uma jornada de trabalho de 14 horas diárias, com direito a duas de descanso. Na sociedade idealizada por Morus, a Ilha de Utopia, os trabalhadores teriam seis horas consagradas ao trabalho, seguidas de duas de repouso.

Em uma passagem do livro, Morus comenta que "cada um é livre para ocupar como quiser as horas compreendidas entre o trabalho, o sono e as refeições" (2010, p. 
77). Após as refeições da noite, haveria uma hora de passatempos: "no verão, nos jardins; no inverno, nas salas comuns que servem também de refeitório. Ali toca-se música, conversa-se.” (MORUS, 2010, p. 77).

O Direito à preguiça não possui um conteúdo explicitamente utópico, mas é obra contestadora, como a obra de Morus, em sua essência. Em ambas, reivindica-se a preguiça ou a ociosidade aos trabalhadores. Lafargue poderia ter citado Morus em seu opúsculo, o que não geraria estranheza no leitor mais politizado.

Para Lafargue, a preguiça, seja nos jardins ou nas salas aquecidas, tem de ser exercida e atualizada pelos trabalhadores. Para Benjamin, poder-se-ia pensar na projeção de um longa-metragem no canto da sala aquecida ou no jardim, fazendo do cinema a autêntica experiência estética de massa.

\section{Referências}

ALBORNOZ, S. G. Sobre O direito à preguiça de Paul Lafargue. Cadernos de Psicologia Social do Trabalho, São Paulo, v. 11, n. 1, p. 1-17, 2008.

ARENDT, Hannah. A condição humana. Tradução de Adriano Correia. 11. ed. São Paulo: Forense Universitária, 2010.

BENJAMIN, Walter. A obra de arte na época de suas técnicas de reprodução. Tradução de José Lino Grünevald. São Paulo: Abril, 1975. (Coleção Os pensadores: textos escolhidos).

1989.

Charles Baudelaire: um lírico no auge do capitalismo. São Paulo: Brasiliense,

Passagens. Tradução de Irene Aron e Cleonice Paes Barreto Mourão. Belo Horizonte: Ed. da UFMG, 2006.

BENJAMIN, W; SCHOLEM, G. Correspondência. Tradução de Neuza Soliz. São Paulo: Perspectiva, 1993. (Coleção Debates: Filosofia).

DE MASI, D.(Org.) A economia do ócio. Rio de Janeiro: Sextane, 2001.

HARDMAN, F. F. Introdução: trabalho e lazer no movimento operário. In: LAFARGUE, Paul. $O$ direito à preguiça: a religião do capital. 3. ed. São Paulo: Kairós, 1983, pp. 13-20.

KONDER, L. Walter Benjamin: o marxismo da melancolia. 3. ed. Rio de Janeiro: Civilização Brasileira, 1999.

LAFARGUE, P. O direito à preguiça. Tradução de J. Teixeira Coelho. São Paulo: Hucitec, UNESP, 1999. 
MAERK, J. El derecho a la pereza, de Paul Lafargue. Revista Mexicana del Caribe, Mexico, ano 5, n. 9, p. 229-237, 2000.

MORUS, Thomas. A utopia. Tradução de Paulo Neves. Porto Alegre: L\&PM, 2010 (Coleção L\&PM Pocket, v. 76).

MARIE, W. Apresentação de Paul Lafargue: Le droit a la paresse: refutation du Droit au Travail de 1848. s. d.; s. ed. Disponível em: 〈http://wmarie.free.fr/pub/paresse.pdf> Acesso em: 02 set. 2010.

WEBER, Max. A ética protestante e o espírito do capitalismo. 2. ed., rev. São Paulo: Thompson, 2001. 